\title{
Stage-dependent suppression of the formation of dentin-resorbing multinuclear cells with migration inhibitory factor in vitro
}

\author{
TAKASHI KIKUIRI $^{1 *}$, YOSHITAKA YOSHIMURA ${ }^{2 *}$, FUTOSHI TABATA $^{1}$, \\ TOMOKAZU HASEGAWA ${ }^{3}$, JUN NISHIHIRA ${ }^{4}$ and TETSUO SHIRAKAWA ${ }^{5,6}$
}

\author{
Departments of ${ }^{1}$ Dentistry for Children and Disabled Person, and ${ }^{2}$ Molecular Cell Pharmacology, Hokkaido University \\ Graduate School of Dental Medicine, Sapporo; ${ }^{3}$ Department of Pediatric Dentistry, Iwate Medical University, Morioka; \\ ${ }^{4}$ Department of Medical Management and Informatics, Hokkaido Information University, Ebetsu; \\ ${ }^{5}$ Department of Pediatric Dentistry; ${ }^{6}$ Division of Oral and Craniomaxillofacial Research, \\ Dental Research Center, Nihon University School of Dentistry, Tokyo, Japan
}

Received August 30, 2011; Accepted September 28, 2011

DOI: $10.3892 /$ etm.2011.362

\begin{abstract}
The macrophage migration inhibitory factor (MIF) is a crucial mediator of immune responses and is known to play a pivotal role in cell proliferation and differentiation. In this study, we assessed whether MIF exerts regulatory effects on osteoclast formation in bone marrow cells and, if so, by what mechanism. Bone marrow cells were either co-cultured with MC3T3-E1 cells or cultured with macrophage-colony stimulating factor (M-CSF) and the soluble form of the receptor activator of the nuclear factor $-\kappa B$ ligand (RANKL). Under the influence of MIF, the formation of osteoclastic multinuclear cells was examined. The number of multinuclear TRAP-positive cells formed in the co-culture was significantly reduced when MIF $(\geq 0.1 \mu \mathrm{g} / \mathrm{ml})$ was exogenously applied during the third and fourth days of the 6-day cultivation period. MIF affected neither the number of mononuclear TRAP-positive cells induced with M-CSF and RANKL, nor the expression of RANKL and osteoprotegerin in MC3T3-E1 cells. TRAP-positive cells cultured on dentin slices with MIF showed lower dentin-resorbing activity than those cultured without MIF. These results suggest that MIF has no regulatory roles in the differentiation of bone marrow cells to mononuclear TRAP-positive cells, but has inhibitory effects on the formation of mature osteoclasts by preventing cell fusion, which may eventually interfere with the osteoclast-mediated dentin resorption.
\end{abstract}

Correspondence to: Dr Yoshitaka Yoshimura, Department of Molecular Cell Pharmacology, Hokkaido University Graduate School of Dental Medicine, Kita 13 Nishi 7, Kita-ku, Sapporo 060-8586, Japan

E-mail: yoshi@den.hokudai.ac.jp

${ }^{*}$ Contributed equally

Key words: macrophage migration inhibitory factor, osteoclast, osteoblast

\section{Introduction}

Similar to bone resorption by osteoclasts, root resorption of deciduous teeth progresses with the activation of odontoclasts of macrophage lineage under physiological conditions (1). In the late stage of root resorption, a large number of TRAP-positive odontoclasts are seen on the resorbing dentin surfaces $(1,2)$. The activity of such monocyte-derived TRAP-positive cells against calcified hard tissues is prominent when they show a multinuclear giant cell-like phenotype. The giant cell-like mature osteoclasts are differentiated from mononuclear osteoclastic cells that develop from osteoclast precursor cells (3). It has been shown that mononuclear osteoclastic cells fuse with each other to form multinuclear cells (MNCs) during the process of maturation, and that mature osteoclasts usually contain several or more nuclei (4). The formation of osteoclasts requires two cellular factors: the macrophage-colony stimulating factor (M-CSF), also known as colony stimulating factor-1, and the receptor activator of the nuclear factor- $\kappa \mathrm{B}$ ligand (RANKL) (5). M-CSF is indispensable for proliferation and differentiation of osteoclast precursor cells that develop from hemopoietic progenitor cells (6). RANKL is a member of the tumor necrosis factor (TNF) family of cytokines and can induce the differentiation of osteoclasts from the precursor cells in the presence of M-CSF (4). It has been reported that the formation of multinuclear osteoclasts is influenced by various cytokines, such as interleukin (IL)-1, IL-6, IL-11 $(7,8)$ and TNF- $\alpha$ (9).

The macrophage migration inhibitory factor (MIF) has been characterized as a pro-inflammatory cytokine (10) produced by T-lymphocytes, and has been shown to be associated with the migration of macrophages during delayed-type hypersensitivity $(11,12)$. It has been shown that MIF not only plays a role in the immune system, but that it is also involved in cell proliferation and differentiation in a variety of organs (13-15). Onodera et al (16) reported that matrix metalloproteinase-13 mRNA expression in osteoblasts was up-regulated by MIF, suggesting that MIF takes part in osseous metabolism. As hemopoietic progenitor cells that differentiate into osteoclast precursor cells are of macrophage lineage $(4,17)$, it 
is possible that MIF influences the differentiation or activity of osteoclasts. Although analyses of bone marrow cells isolated from both wild-type and MIF transgenic mice have not provided evidence of the direct effects of MIF on osteoclast formation (18), it has been shown that trabecular bone volume in the femurs and vertebrae of MIF-deficient mice is decreased compared to wild-type mice, suggesting that MIF-deficiency facilitates osteoclastic bone resorption (19).

Osteoblasts or stromal cells play a role in osteoclast differentiation, and the interaction of these cells with osteoclast precursors is crucial for the formation of mature osteoclasts (20). Osteoblasts are known to express RANKL, that promotes the differentiation and activation of osteoclasts, and they also produce osteoprotegerin (OPG), a member of the TNF receptor superfamily, that suppresses bone resorption by inhibiting osteoclast formation (21). When the root resorption of deciduous teeth occurs, hematopoietic progenitor cells migrate from blood vessels of the periodontal ligament and alveolar bone toward the root surface (1). In parallel with the activation of osteoclasts, periodontal tissues adjacent to the resorbing root surface degenerate without inflammation (22). As the periodontal fibroblasts prevent osteoclast formation in a steady state condition (23), it is plausible that RANKL-expressing osteoblasts play a predominant role in the differentiation and/or maturation of osteoclasts around the tooth root, and MIF may affect the osteoblast activity and regulate root resorption during the tooth shedding stage. In the present study, we examined the role of MIF in the formation and action of dentin-resorbing multinuclear osteoclasts derived from mouse bone marrow cells.

\section{Materials and methods}

Reagents and culture media. MC3T3-E1 cells and mouse bone marrow cells were cultured in $\alpha$-minimal essential medium ( $\alpha$-MEM; Gibco BRL, Grand Island, NY, USA) containing $10 \%$ fetal bovine serum (FBS; Hyclone, Logan, UT, USA). The recombinant soluble form of human RANKL was purchased from PeproTech, Inc. (Rocky Hill, NJ, USA). Recombinant human M-CSF was purchased from Austral Biologicals (San Ramon, CA, USA). Recombinant MIF was expressed in Escherichia coli BL21/DE3 (Novagen, Madison, WI, USA) and purified as described previously (24). It contained $<1 \mathrm{pg}$ of endotoxin $/ \mu \mathrm{g}$ protein, as determined by the chromogenic Limulus amebocyte assay (BioWhittaker, Walkersville, MD, USA).

Osteoclast formation in a co-culture system. Mouse bone marrow cells were collected from 4-week-old C57BL/6 mice by flushing the femoral shafts with a 26 -gauge sterile needle. The cells $\left(1 \times 10^{6}\right.$ cells/well) were seeded on confluent MC3T3-E1 osteoblast-like cells $\left(2 \times 10^{5}\right.$ cells/well $)$ cultured in 24-well dishes with $\alpha$-MEM containing 10\% FBS, $10 \mathrm{nM}$ 1- $\alpha, 25$-dihydroxyvitamin $\mathrm{D}_{3}$ (vitamin $\mathrm{D}_{3}$ ) and $100 \mathrm{nM}$ dexamethasone (Dex). MIF was applied to the cells by dissolving in the medium at concentrations of $0.01,0.1$ and $1.0 \mu \mathrm{g} / \mathrm{ml}$, and the medium $(1 \mathrm{ml} /$ well $)$ was changed every 2 days. The experimental work was reviewed and approved by the Animal Care Committee of Hokkaido University Graduate School of Dental Medicine. After 6 days of co-culture, the cells were fixed with $10 \%$ formaldehyde in PBS for $10 \mathrm{~min}$ at room temperature. After washing with PBS, the cells were treated with an acetone/ethanol mixture (50:50, v/v) for $1 \mathrm{~min}$ at room temperature. Then, the cells were dried naturally and stained for TRAP by incubating in $0.1 \mathrm{M}$ sodium acetate buffer (pH 5.0) containing AS-MX phosphate (Sigma) and Fast red violet LB salt (Sigma) in the presence of $50 \mathrm{mM}$ sodium tartrate as described previously (25). Rinsed with distilled water, TRAP-positive MNCs were counted by using a light microscope (Eclipse 80i; Nikon, Tokyo, Japan).

Quantitative RT-PCRfor RANKLmRNA.ConfluentMC3T3-E1 cells $\left(2 \times 10^{5}\right.$ cells/well) on 24 -well dishes were cultured with $\alpha$-MEM containing $10 \%$ FBS, $10 \mathrm{nM}$ vitamin $\mathrm{D}_{3}, 100 \mathrm{nM}$ Dex and MIF $(0.01,0.1$ and $1.0 \mu \mathrm{g} / \mathrm{ml})$ for 24 or $48 \mathrm{~h}$. Total RNA (tRNA) was prepared from the cells with ISOGEN (Nippon Gene Co., Tokyo, Japan) according to the manufacturer's instructions. The tRNA was treated with DNase I (Takara Bio Co., Kyoto, Japan) for $1 \mathrm{~h}$ at $37^{\circ} \mathrm{C}$ to remove genomic DNA.

Real-time reverse transcriptase-polymerase chain reaction (RT-PCR) was performed for the quantification of RANKL and GAPDH mRNAs with Smart Cycler (Cepheid, Sunnyvale, CA, USA). Single-stranded cDNA was synthesized from $2 \mu \mathrm{g}$ of the treated RNA as follows: the tRNA was incubated with $0.5 \mu \mathrm{g}$ oligo $(\mathrm{dT})_{12-18}$ primer (Gibco Brl) at $70^{\circ} \mathrm{C}$ for $10 \mathrm{~min}$, then chilled on ice and mixed with $1 \mu 110 \mathrm{mM}$ dNTP (Gibco-BRL) for $5 \mathrm{~min}$ at $25^{\circ} \mathrm{C}$. The mixture was reacted with $1 \mu 1$ Superscript II RNase H-reverse transcriptase (Gibco $\mathrm{Brl}$ ) for $10 \mathrm{~min}$ at $25^{\circ} \mathrm{C}$, which was followed by incubation at $42^{\circ} \mathrm{C}$ for $50 \mathrm{~min}$. PCR for the cDNAs was set up in a Smart Cycler reaction tube (Cepheid). According to the instruction of Takara Ex Taq R-PCR version kit (Takara Bio), $0.25 \mu \mathrm{l}$ Ex Taq R-PCR, $2.5 \mu 1$ 10X R-PCR buffer, $0.3 \mu 1250 \mathrm{mM} \mathrm{Mg}^{2+}$ solution for R-PCR, $0.75 \mu \mathrm{l}$ dNTP mixture and 2.5 $\mu \mathrm{l} \mathrm{SYBR-}$ Green I (dilution 1:3,000) were mixed with $2 \mu \mathrm{l}$ sample cDNA,

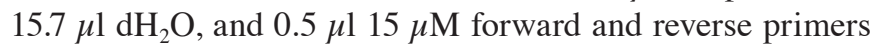
(RANKL, 5'-TAT GAT GGA AGG CTC ATG GT-3' and 5'-TGT CCT GAA CTT TGA AAG CC-3'; GAPDH, 5'-CGG AGT CAA CGG ATT TGG TCG TAT-3' and 5'-AGC CTT CTC CAT GTT GGT GAA GAC-3').

The PCR reaction was performed at the following temperature cycle: a denaturation step at $95^{\circ} \mathrm{C}$ for $30 \mathrm{sec}$ and 50 cycles of denaturation at $95^{\circ} \mathrm{C}$ for $1 \mathrm{sec}$, annealing at $55^{\circ} \mathrm{C}$ for $15 \mathrm{sec}$ and extension at $72^{\circ} \mathrm{C}$ for $15 \mathrm{sec}$. The amplification for RANKL and GAPDH cDNAs was carried out simultaneously and the final products were quantified by measuring fluorescence from SYBR-Green I bound to the double-stranded cDNA in the reaction tubes. The fluorescence intensity from the SYBR-Green I-labeled RANKL cDNA was normalized to that from the labeled GAPDH cDNA.

Measurement of $O P G$ in the culture media. Confluent MC3T3-E1 cells $\left(2 \times 10^{5}\right.$ cells/well) on $24-w e l l$ dishes were cultured with $\alpha$-MEM containing $10 \%$ FBS, $10 \mathrm{nM}$ vitamin $\mathrm{D}_{3}, 100 \mathrm{nM}$ Dex and $\operatorname{MIF}(0.01,0.1$ and $1.0 \mu \mathrm{g} / \mathrm{ml})$ for 24 or $48 \mathrm{~h}$. The concentration of OPG in the conditioned medium was measured using a mouse OPG immunoassay kit (ANALYZA Immunoassay System; Techne Co., Minneapolis, MN, USA) that was based on the sandwich enzyme immunoassay technique. In brief, standard solutions and the collected 

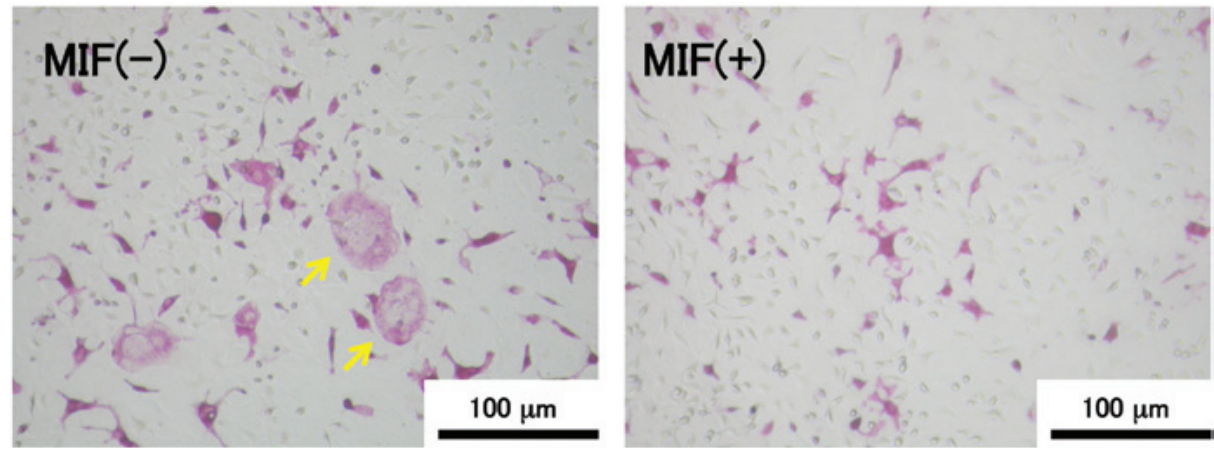

Figure 1. Effects of MIF on the induction of TRAP-positive cells in co-culture. Mouse bone marrow cells were seeded on confluent MC3T3-E1 osteoblast-like cells and cultured for 6 days with $\alpha$-MEM containing FBS, vitamin $\mathrm{D}_{3}$ and Dex in the presence or absence of MIF. MIF(-): cells co-cultured without MIF. $\operatorname{MIF}(+)$, cells co-cultured in the presence of MIF $(0.1 \mu \mathrm{g} / \mathrm{ml})$. Arrows, mature osteoclasts containing five or more nuclei.

samples were placed in a 96-well microplate pre-coated with monoclonal antibody specific to mouse OPG and incubated for $2 \mathrm{~h}$ at room temperature. After washing, a peroxidaselabeled polyclonal antibody specific to OPG was added to each well and incubated for $2 \mathrm{~h}$. Then, unbound antibody-enzyme reagent was removed by washing and a substrate reagent was added to the wells. Following incubation for $30 \mathrm{~min}$ at room temperature, absorbance at $450 \mathrm{~nm}$ was measured with a microplate reader.

Osteoclast formation in a bone marrow cell culture. Bone marrow cells were collected from 4-week-old C57BL/6 mice as described above. They were applied to a Sephadex G-10 column (Pharmacia, Uppsala, Sweden) and incubated for $45 \mathrm{~min}$ at $37^{\circ} \mathrm{C}$. Then, the cell suspension was passed through the column with the addition of $\alpha$-MEM containing $10 \%$ FBS and collected. By this process, adhesive cells mixed in the extract of bone marrow were trapped in the column (26), and we used the passed cells as osteoclast precursors for the subsequent experiment. The cells $\left(2 \times 10^{4}\right.$ cells/well $)$ were plated in 24-well plates with $1 \mathrm{ml}$ of $\alpha$-MEM containing $10 \% \mathrm{FBS}$, $5 \mathrm{ng} / \mathrm{ml} \mathrm{M}-\mathrm{CSF}, 50 \mathrm{ng} / \mathrm{ml}$ soluble RANKL and $0.1 \mu \mathrm{g} / \mathrm{ml} \mathrm{MIF}$. After 6 days of culture, the cells were fixed and stained for TRAP as described earlier.

Scanning electron microscope (SEM) observation of resorption pits. The activity of osteoclasts in terms of degrading calcified tissue was assessed by a comparison of the size of the resorption pits which appeared on mammoth tusk-derived dentin slices (Hokudo Co., Sapporo, Japan). Osteoclast precursor cells $\left(2 \times 10^{4}\right.$ cells/well) were plated on a dentin slice (14 $\mathrm{mm}$ in diameter, $300 \mu \mathrm{m}$ in thickness) placed in the well of culture plates containing $1 \mathrm{ml}$ of $\alpha$-MEM supplemented with $10 \%$ FBS, $5 \mathrm{ng} / \mathrm{ml}$ M-CSF, $50 \mathrm{ng} / \mathrm{ml}$ soluble RANKL and $0.1 \mu \mathrm{g} / \mathrm{ml} \mathrm{MIF}$. After 6 days of culture, the cells were removed and the dentin slices were dehydrated through a graded series of ethanol and critical-point-dried with liquid $\mathrm{CO}_{2}$. The dentin slices were coated with platinum and palladium in an ion coater (E-1030; Hitachi, Tokyo, Japan) and observed with (SEM).

Statistical analysis. The results were expressed as the means \pm SD. Overall comparisons were made using ANOVA and statistical differences between the groups were determined by

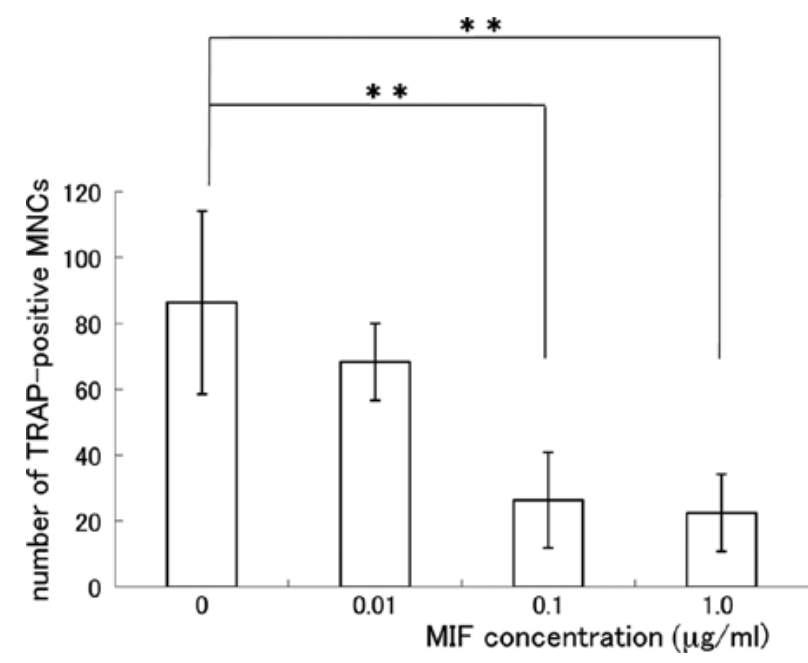

Figure 2. Dose-dependent effects of MIF on the formation of TRAP-positive MNCs in the co-culture. After co-culturing MC3T3-E1 cells and bone marrow cells for 6 days with $\operatorname{MIF}(0,0.01,0.1$ and $1.0 \mu \mathrm{g} / \mathrm{ml})$, the number of TRAP-positive MNCs that contained two or more nuclei was counted. Data are presented as the means \pm SD ( $n=6$ for each group). Significant differences between groups $(\mathrm{P}<0.01)$ are indicated with asterisks.

Bonferroni's test. Data with a P-value $<0.05$ were considered significant.

\section{Results}

Effects of MIF on osteoclast formation in the co-culture. TRAP-positive MNCs were observed in the 6-day co-culture of MC3T3-E1 cells and bone marrow cells in the presence of vitamin $\mathrm{D}_{3}$ and Dex (Fig. 1). The relationship between the MIF concentration and the number of TRAP-positive MNCs is shown in Fig. 2. The formation of TRAP-positive MNCs was significantly suppressed in the MIF-treated co-culture and the effect of MIF was dose-dependent. The suppressive effect of MIF on the osteoclast formation was remarkable at the concentrations of 0.1 and $1.0 \mu \mathrm{g} / \mathrm{ml}$. To determine the exact stage at which MIF influenced the formation of MNCs, we divided the 6-day cultivation period into 3 stages: the early stage (days 1-2), the middle stage (days 3-4) and the late stage (days 5-6). Eight co-culture groups were prepared and MIF $(0.1 \mu \mathrm{g} / \mathrm{ml})$ was applied at each of the stages of a 2-day period, as indicated in Fig. 3. The number of MNCs was apparently 


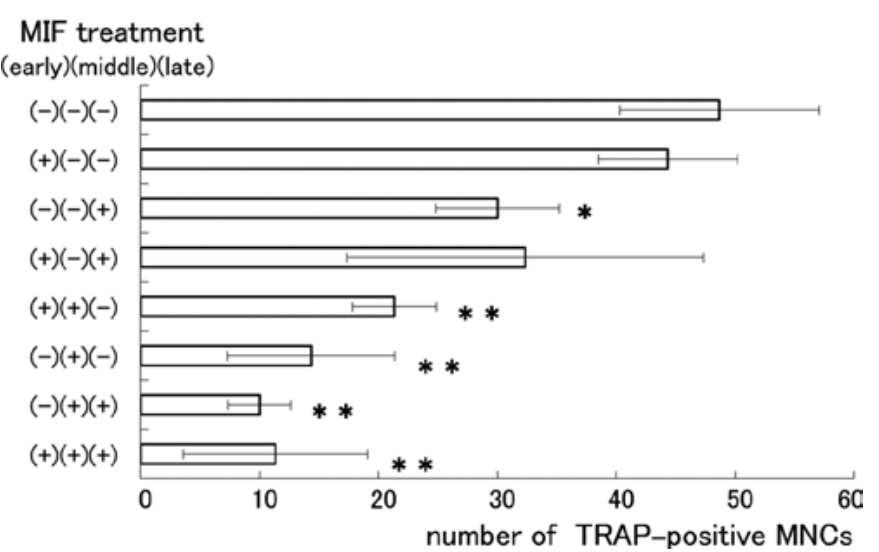

Figure 3. Time-dependent effects of MIF on the formation of TRAP-positive MNCs in the co-culture of MC3T3-E1 cells and bone marrow cells. The 6-day cultivation period was divided into 3 stages (2 days each); the stage when MIF $(0.1 \mu \mathrm{g} / \mathrm{ml})$ was applied to the culture is indicated as $(+)$, and the stage when MIF was not applied to the culture is indicated as (-). The early, middle and late stages are indicated in a row from left to right. TRAP-positive MNCs that contained two or more nuclei were counted. Data are presented as the means $\pm \mathrm{SD}$ ( $\mathrm{n}=6$ for each group). ${ }^{* *} \mathrm{P}<0.01,{ }^{*} \mathrm{P}<0.05$.

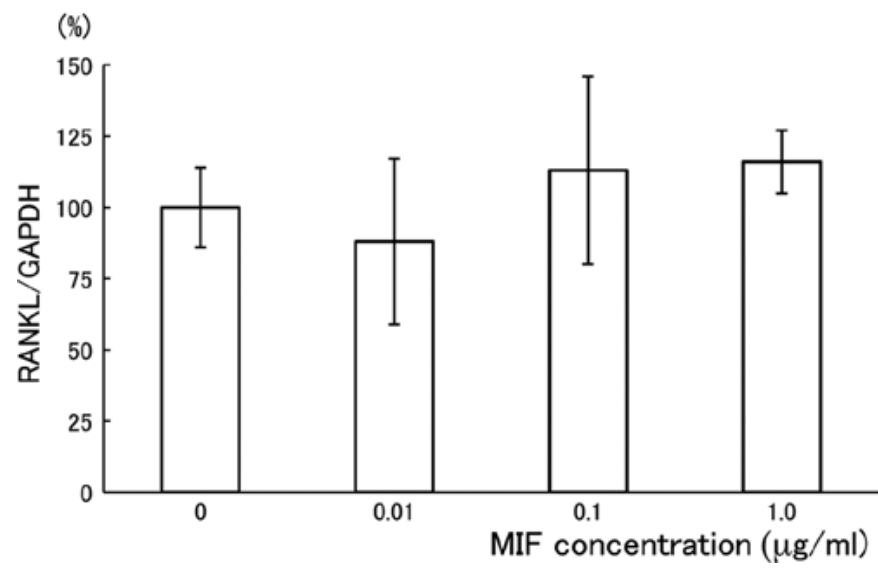

Figure 4. Effects of MIF on the RANKL mRNA expression in MC3T3-E1 cells. After 24-h cultivation of MC3T3-E1 cells with various concentrations of MIF, mRNAs of RANKL and GAPDH expressed in the MC3T3-E1 cells were measured. Relative expression of RANKL mRNA to that of GAPDH mRNA (normalized by the control value) are indicated. There was no difference in RANKL mRNA expression among the cells treated with different concentrations of MIF. Data are presented as the means \pm SD ( $n=6$ for each group).

reduced in the groups where MIF was applied at the middle and late stages in the cultivation period. The suppressive effect of MIF on the formation of MNCs was most remarkable when applied at the middle stage. The present results are consistent with a recent report demonstrating that the formation of MNCs in a culture of RAW 264.7 cells, a mouse macrophage cell line, was suppressed more effectively in the presence of RANKL when MIF was applied at the last 2 days in a 4-day culture (19). It is noteworthy that the middle stage in our experiment coincides with the time when multinuclear osteoclasts were first confirmed in the same co-culture system (27).

Effects of MIF on the expression of RANKL and OPG in MC3T3-E1 cells. To investigate whether the suppressive effect of MIF on the formation of MNCs is dependent on the amounts of RANKL and/or OPG that are produced by

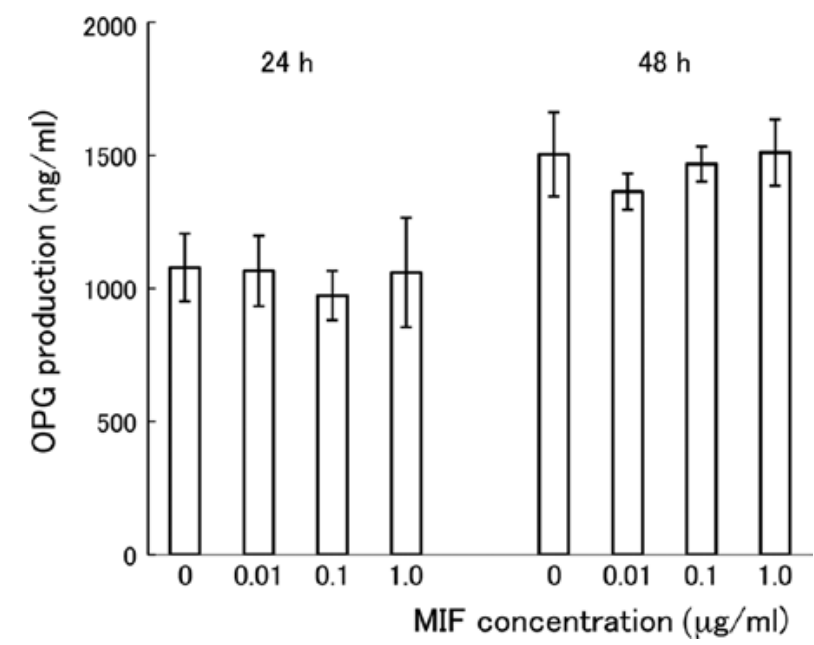

Figure 5. Effects of MIF on the production of OPG in MC3T3-E1 cells. After 24- or 48-h cultivation of MC3T3-E1 cells with various concentrations of MIF, OPG in the conditioned media was measured. There was no difference in OPG concentration among the media treated with different concentrations of MIF for the identical period, although longer cultivation increased OPG concentration in the media. Data are presented as the means $\pm \mathrm{SD}$ ( $\mathrm{n}=6$ for each group).

MC3T3-E1 cells (28), we measured RANKL mRNA and OPG production in the MC3T3-E1 cell culture. The expression of RANKL mRNA was evaluated using quantitative RT-PCR, and the result is shown in Fig. 4 as a relative expression ratio of RANKL to GAPDH. After the 24-h cultivation period with MIF, there was no substantial effect of the treatment on the RANKL mRNA expression in MC3T3-E1 cells. The treatment of MC3T3-E1 cells with MIF for $48 \mathrm{~h}$ under the same conditions also had no effect (data not shown). For the assay of OPG production by MC3T3-E1 cells, conditioned media were collected from MC3T3-E1 cell cultures treated with MIF for 24 or 48 h. As shown in Fig. 5, there was no significant difference in the concentration of OPG among the cultures treated with different doses of MIF. Cultivation of the cells for a longer period with MIF ( 24 vs. $48 \mathrm{~h}$ ) resulted in a further accumulation of OPG in the media, but there was no difference in the OPG concentration among the cultures treated with different doses of MIF. We did not find a difference in the number of MC3T3-E1 cells per well among the cultures after the treatment with MIF (data not shown).

Effects of MIF on the osteoclast formation in the bone marrow cell culture. Osteoclast formation was observed in the mouse bone marrow cells cultured with M-CSF and soluble RANKL for 6 days. Without applications of these factors, TRAP-positive cells were not induced, and treatment of the bone marrow cells with either M-CSF or RANKL had no effect (data not shown). As shown in Fig. 6A, TRAP-positive mononuclear cells were present in MIF-treated cultures and the cell number was not smaller than that in the control cultures. However, the number of MNCs was significantly smaller in the MIF-treated cultures compared to the control cultures $(\mathrm{P}<0.05)$. When MNCs were classified into subgroups by the number of nuclei (Fig. 6B), it became apparent that there were very few TRAP-positive MNCs having five or more nuclei in the MIF-treated cultures. The ratio of MNC formation in the absence of MIF was $14.6 \%$ of the total TRAP-positive cells and in the presence of MIF 
A

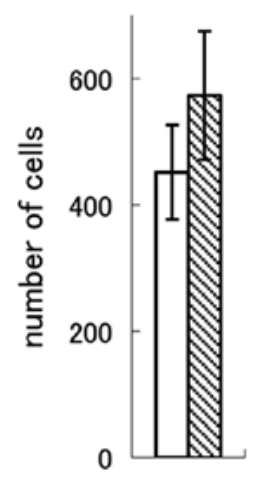

mononuclear

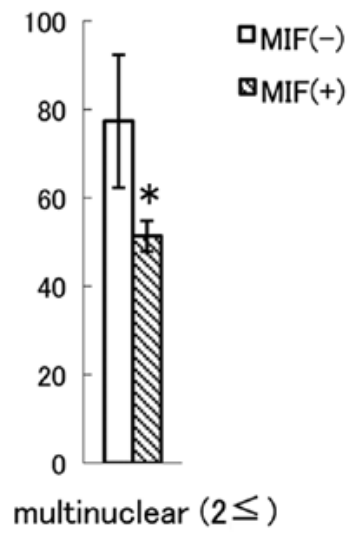

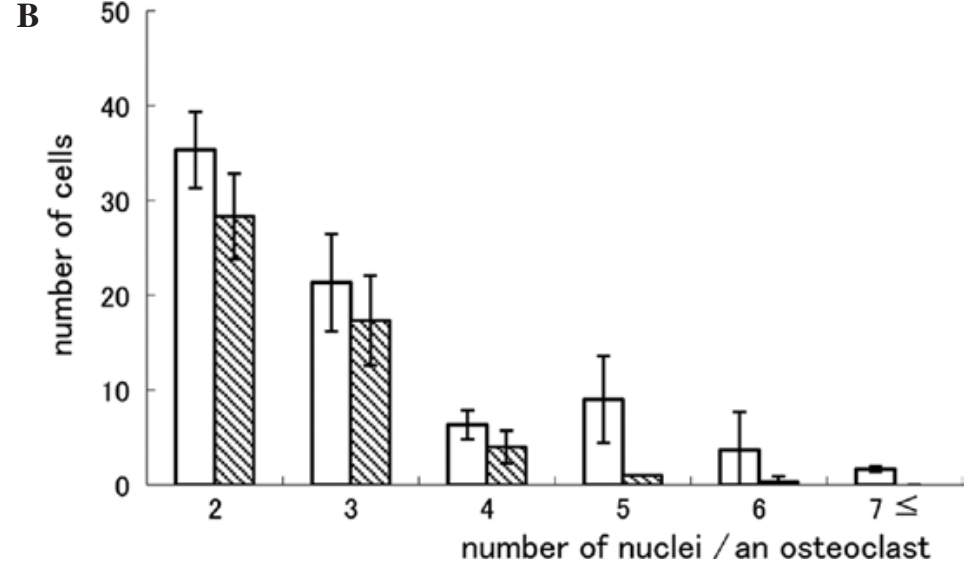

Figure 6. Multinucleation of osteoclasts was influenced by MIF. Mouse bone marrow cells were cultured either with or without MIF ( $0.1 \mu \mathrm{g} / \mathrm{ml})$ in the presence of M-CSF and soluble RANKL for 6 days. (A) The numbers of TRAP-positive mononuclear cells and MNCs (with two or more nuclei) were compared between the control and MIF-treated cultures. There was no significant difference in the number of TRAP-positive mononuclear cells between the cultures. However, the number of MNCs in the MIF-treated culture was significantly less than that in the control culture $\left({ }^{*} \mathrm{P}<0.05\right)$. (B) The number of TRAP-positive MNCs classified into subgroups by the number of nuclei. Very few TRAP-positive MNCs had five or more nuclei in the MIF-treated culture.
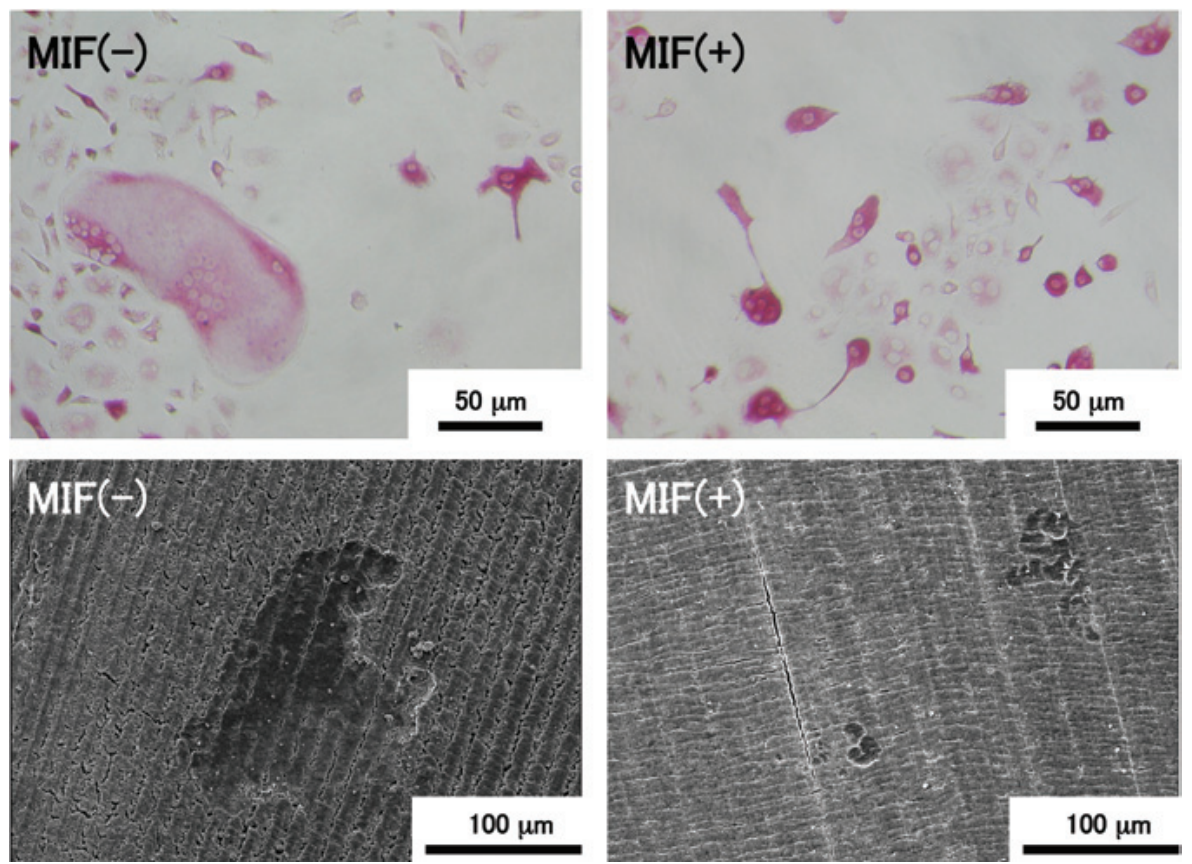

Figure 7. Presence of large resorption pits on dentin slices in the control culture, but not in the cell culture treated with MIF. Top: representative images of TRAP-positive cells in the bone marrow cell culture. A multinuclear giant cell with more than ten nuclei was present in the control culture (left), but such a large cell was not found in the $0.1 \mu \mathrm{g} / \mathrm{ml}$ MIF-treated culture (right). Bottom: resorption pits formed on dentin slices by osteoclasts. A large resorption pit of $>100 \mu \mathrm{m}$ in diameter was found to be formed on the control slice (left), but such a large pit was absent on the slices exposed to MIF-treated cells (right).

it was $9.4 \%$. There was no difference in the total number of the nuclei of TRAP-positive cells between the control and MIF-treated cultures, and the numbers were $696.1 \pm 81.5$ and $706 \pm 117.5 /$ well, respectively. Fig. 7 shows representative images of TRAP-positive cells in the bone marrow cell culture and resorption pits formed by osteoclasts on the dentin slices. TRAP-positive multinuclear giant cells with more than ten nuclei were present in the control culture, as shown in the upper left image, although such a large cell was not found in the MIF-treated culture (upper right image). The maximum number of nuclei in individual MNC in the control culture was 17 , but that in the MIF-treated culture was 6 . TRAPpositive cells containing a few nuclei were present in both the control and MIF-treated cultures, and the majority of the TRAP-positive cells in both cultures were mononuclear cells. Resorption pits formed on the dentin slices were visualized by SEM (Fig. 7; lower images). A large resorption pit of $>100 \mu \mathrm{m}$ in diameter was formed on the control slice, but such a large pit was never found on the slices exposed to MIF-treated bone marrow cells.

\section{Discussion}

In the present study, we examined the role of MIF in the formation of dentin-resorbing MNCs from mouse bone marrow cells, and showed that MIF inhibited the formation 
of MNCs by preventing cell fusion at the middle stage and, to a lesser extent, the late stage of the 6-day cultivation period in co-culture with MC3T3-E1 cells. Osteoblast/stromal cells play a role in the differentiation of osteoclasts by producing RANKL, an essential factor for the osteoclast formation. They also produce OPG that suppresses osteoclast formation by acting as a decoy receptor for RANKL (4). It can be speculated that the inhibitory effect of MIF on the formation of MNCs may be mediated by the suppression of RANKL or by the up-regulation of OPG, as the amount of these factors is closely related to the formation of MNCs, as shown in our previous study (23). However, as is evident from the present experiments using MC3T3-E1 cell culture, neither RANKL mRNA expression nor OPG production was influenced by MIF. In these experiments, 24- or 48-h exposure of MC3T3-E1 cells to $1.0 \mu \mathrm{g} / \mathrm{ml}$ of MIF, which is 10 -fold higher than the dose sufficient to inhibit formation of MNCs in the co-culture, had no effect. Exposure of murine calvarial osteoblasts to MIF for 12 or $24 \mathrm{~h}$ also had no substantial effects on cellular RANKL and OPG mRNA levels (18). Although these results do not exclude the possibility that MIF has some effects on the production of other cytokines or factors in MC3T3-E1 cells and influences the maturation of osteoclasts, it is apparent that MIF does not affect the RANKL-dependent intercellular processes of osteoclast differentiation from the precursors.

MNCs can be induced from bone marrow cells in a culturing condition that does not contain osteoblastic cells (29). Instead of the cooperation with osteoblastic cells, TRAP-positive cells were induced abundantly in the culture of bone marrow cells stimulated with M-CSF and RANKL. We did not find a significant difference in the number of mononuclear osteoclastic cells between the control and MIF-treated cultures, although a slightly larger number of mononuclear osteoclastic cells was observed in the MIF-treated cultures. By contrast, a significant reduction in the number of MNCs was observed in the MIF-treated cultures and the suppressive effect of MIF on the fusion of osteoclastic cells was evident when the number of mature osteoclasts was counted; we found very few MNCs containing five or more nuclei in the MIF-treated cultures.

For the isolation of bone marrow cells, we removed osteoblastic and fibroblastic cells effectively from the heterogenous cell mixture extracted from mouse femoral shafts by purifying it using a Sephadex G-10 column in which adhesive cells, such as osteoblasts, were trapped. This treatment excluded the possible methodological flaw such that MIF activated contaminated cells and affected the maturation of osteoclasts. Our histological studies further support the direct action of MIF on differentiated osteoclasts. In contrast to the formation of extremely large osteoclasts containing more than ten nuclei in the MIF-free culture, mature MNCs were rarely found in the bone marrow cell culture treated with MIF. The assay of pit formation on dentin slices suggests a close relationship between the sizes of MNCs and their dentin-resorbing potential. The large resorption pits formed on the dentin surface mean strong phagocytic action of giant osteoclasts. Taken together with the results reported by another group (19), it can be concluded that MIF inhibits the formation of MNCs by preventing the fusion of osteoclastic cells.

Osteoclast formation occurs through a cell differentiation pathway that implies the formation of osteoclast precursors from hemopoietic cells, subsequent differentiation of the precursors to mononuclear osteoclastic cells, and a process of cell fusion to form multinuclear osteoclasts (30). The processes of the osteoclast differentiation require several days in vitro; in fact, it took 4 days to form MNCs in the co-culture of mouse bone marrow cells and MC3T3-E1 cells (27). To specify the time when MIF affected the formation of MNCs, we divided the 6-day cultivation period into 3 stages, and bone marrow cells and MC3T3-E1 cells were co-cultured either with or without MIF by changing the medium every 2 days. We paid particular attention to adjusting the number of both bone marrow cells and MC3T3-E1 cells in the culture dishes at the beginning of co-culture. When MIF was applied to the co-culture at the middle stage, the formation of MNCs was markedly inhibited. The application of MIF at the late stage had a substantial, although lesser effect on the formation of MNCs compared to the MIF application at the middle stage. By contrast, the application of MIF at the early stage had no effect, or rather slightly promoted MNC formation. The middle stage corresponds to the period when mononuclear osteoclastic cells are formed nearly completely and they start to fuse with each other in the experimental condition $(27,30)$. The present findings strongly indicate that MIF exerts an inhibitory effect on the formation of MNCs by preventing the multinucleation of osteoclasts, and that MIF has little effect on the differentiation of osteoclast precursors to mononuclear osteoclastic cells.

The mechanism of inhibition of the formation of mature osteoclasts by MIF has not yet been elucidated. In order to further investigate the action of MIF, the process of cell fusion must be clarified. Kukita et al (31) showed that the dendritic cell-specific transmembrane protein (DC-STAMP), a putative seven-transmembrane-spanning receptor, was induced in osteoclastic cells by RANKL, and that target inhibition of this molecule by small interfering RNAs suppressed the formation of MNCs. Yagi et al (32) also demonstrated that DC-STAMP is essential for the fusion of osteoclast precursor cells and macrophages. Vignery (33) proposed a possible mechanism of the cell fusion; the DC-STAMP-expressing osteoclastic cell acts as the master fusing cell and fuses with a DC-STAMP-negative follower cell. Although the ligand for DC-STAMP has not yet been identified, the possibility that MIF influences the resorption of calcified tissues by exerting some effects on DC-STAMP itself or its ligand is a matter of concern.

There is accumulating evidence that MIF may be associated with juvenile idiopathic arthritis (JIA). A novel 5'-flanking region polymorphism of MIF has been shown to be associated with systemic-onset JIA (34). Systemic-onset JIA patients carrying a -173 single-nucleotide $\mathrm{G}$-to-C polymorphism of the MIF gene (MIF-173*C) had serum and synovial fluid levels of MIF significantly higher than those in patients carrying a MIF- $173^{*} \mathrm{G}$ allele, and the duration of clinical response to intra-articular injection of triamcinolone hexacetonide was significantly shorter in patients carrying the MIF-173* C allele (35). Notably, a clinical survey of panoramic radiographs of school children revealed that dental maturity was significantly advanced in JIA patients compared to healthy children (36). Although the effect of corticosteroids used for the treatment of JIA should also be taken into account, MIF may be involved in the mechanism of altered dental development in JIA children. 


\section{Acknowledgements}

This study was supported in part by KAKENHI (Grant-in-Aid for Scientific Research from the Japan Society for the Promotion of Science: 18390551, 19659544, 22592274 and 21592584); a grant from the 'Strategic Research Base Development' Program for Private Universities from the Ministry of Education, Culture, Sports, Science, and technology, Japan (MEXT, S1001024); a grant from the Dental Research Center, Nihon University School of Dentistry, and the Sato and Uemura Funds from the Nihon University School of Dentistry.

\section{References}

1. Sahara N, Toyoki A, Ashizawa Y, Deguchi T and Suzuki K: Cytodifferentiation of the odontoclast prior to the shedding of human deciduous teeth: an ultrastructural and cytochemical study. Anat Rec 244: 33-49, 1996.

2. Domon T, Yasuda M, Osanai M, et al: Increase in odontoclast nuclei number by cell fusion: a three-dimensional reconstruction of cell fusion of human odontoclasts. Anat Rec 252: 462-471, 1998.

3. Udagawa N, Takahashi N, Akatsu T, et al: Origin of osteoclasts: mature monocytes and macrophages are capable of differentiating into osteoclasts under a suitable microenvironment prepared by bone marrow-derived stromal cells. Proc Natl Acad Sci USA 87: 7260-7264, 1990

4. Suda T, Takahashi N, Udagawa N, Jimi E, Gillespie MT and Martin TJ: Modulation of osteoclast differentiation and function by the new members of the tumor necrosis factor receptor and ligand families. Endocr Rev 20: 345-357, 1999.

5. Lacey DL, Timms E, Tan HL, et al: Osteoprotegerin ligand is a cytokine that regulates osteoclast differentiation and activation. Cell 93: 165-176, 1998.

6. Biskobing DM, Fan X and Rubin J: Characterization of MCSFinduced proliferation and subsequent osteoclast formation in murine marrow culture. J Bone Miner Res 10: 1025-1032, 1995.

7. Lee SK, Kalinowski J, Jastrzebski S and Lorenzo JA: 1,25(OH)2 vitamin D3-stimulated osteoclast formation in spleen-osteoblast cocultures is mediated in part by enhanced IL- $1 \alpha$ and receptor activator of $\mathrm{NF}-\kappa \mathrm{B}$ ligand production in osteoblasts. J Immunol 169: 2374-2380, 2002.

8. Kudo O, Sabokbar A, Pocock A, Itonaga I, Fujikawa Y and Athanasou NA: Interleukin-6 and interleukin-11 support human osteoclast formation by a RANKL-independent mechanism. Bone 32: 1-7, 2003.

9. Lam J, Takeshita S, Barker JE, Kanagawa O, Ross FP and Teitelbaum SL: TNF- $\alpha$ induces osteoclastogenesis by direct stimulation of macrophages exposed to permissive levels of RANK ligand. J Clin Invest 160: 1481-1488, 2000.

10. Calandra T and Roger T: Macrophage migration inhibitory factor: a regulator of innate immunity. Nat Rev Immunol 3 : 791-800, 2003

11. David JR: Delayed hypersensitivity in vitro: its mediation by cell-free substances formed by lymphoid cell-antigen interaction. Proc Natl Acad Sci USA 56: 72-77, 1996.

12. Bloom BR and Bennett B: Mechanism of a reaction in vitro associated with delayed-type hypersensitivity. Science 153: 80-82, 1966.

13. Lanahan A, Williams JB, Sanders LK and Nathans D: Growth factor-induced delayed early response genes. Mol Cell Biol 12: 3919-3929, 1992.

14. Wistow GJ, Shaughnessy MP, Lee DC, Hodin J and Zelenka PS: A macrophage migration inhibitory factor is expressed in the differentiating cells of the eye lens. Proc Natl Acad Sci USA 90: $1272-1275,1993$.
15. Mitchell RA, Metz CN, Peng T and Bucala R: Sustained mitogenactivated protein kinase (MAPK) and cytoplasmic phospholipase A2 activation by macrophage migration inhibitory factor (MIF). Regulatory role in cell proliferation and glucocorticoid action. J Biol Chem 274: 18100-18106, 1999.

16. Onodera S, Nishihira J, Iwabuchi K, et al: Macrophage migration inhibitory factor up-regulates matrix metalloproteinase- 9 and -13 in rat osteoblasts. J Biol Chem 277: 7865-7874, 2002.

17. Danks L, Sabokbar A, Gundle R and Athanasou NA: Synovial macrophage-osteoclast differentiation in inflammatory arthritis. Ann Rheum Dis 61: 916-921, 2002.

18. Onodera S, Sasaki S, Ohshima S, et al: Transgenic mice overexpressing macrophage migration inhibitory factor (MIF) exhibit high-turnover osteoporosis. J Bone Miner Res 21: 876-885, 2006.

19. Jacquin C, Koczon-Jaremko B, Aguila HL, et al: Macrophage migration inhibitory factor inhibits osteoclastogenesis. Bone 45: 640-649, 2009.

20. Katagiri T and Takahashi N: Regulatory mechanisms of osteoblast and osteoclast differentiation. Oral Dis 8: 147-159, 2002.

21. Yasuda H, Shima N, Nakagawa N, et al: Osteoclast differentiation factor is a ligand for osteoprotegerin/osteoclastogenesisinhibitory factor and is identical to TRANCE/RANKL. Proc Natl Acad Sci USA 95: 3597-3602, 1998.

22. Ten Cate AR: Oral Histology: Development, Structure, and Function. Mosby-Year Book, St. Louis, pp325-329, 1994.

23. Hasegawa T, Yoshimura Y, Kikuiri T, et al: Expression of receptor activator of NF-kappa B ligand and osteoprotegerin in culture of human periodontal ligament cells. J Periodontal Res 37: 405-411, 2002.

24. Nishihira J, Kuriyama T, Sakai M, et al: The structure and physiochemical properties of rat liver macrophage migration inhibitory factor. Biochim Biophys Acta 1247: 159-162, 1995.

25. Shibata K, Yoshimura Y, Kikuiri T, et al: Effect of the release from mechanical stress on osteoclastogenesis in RAW264.7 cell. Int J Mol Med 28: 73-79, 2011.

26. Amano H, Yamada S and Felix R: Colony-stimulating factorstimulates the fusion process in osteoclasts. J Bone Miner Res 13: 846-853, 1998.

27. Shirai Y, Yoshimura Y, Yawaka Y, et al: Effect of extracellular calcium concentrations on osteoclast differentiation in vitro. Biochem Biophys Res Commun 265: 484-488, 1999.

28. Deyama Y, Takeyama S, Koshikawa, et al: Osteoblast maturation suppressed osteoclastogenesis in coculture with bone marrow cells. Biochem Biophys Res Commun 274: 249-254, 2000.

29. Yasuda H, Shima N, Nakagawa N, et al: A novel molecular mechanism modulating osteoclast differentiation and function. Bone 25: 109-113, 1990.

30. Tsurukai T, Udagawa N, Matsuzaki K, Takahashi N and Suda T: Roles of macrophage-colony stimulating factor and osteoclast differentiation factor in osteoclastogenesis. J Bone Miner Metab 18: 177-184, 2000.

31. Kukita T, Wada N, Kukita A, et al: RANKL-induced DC-STAMP is essential for osteoclastogenesis. J Exp Med 200: 941-946, 2004

32. Yagi M, Miyamoto T, Sawatani Y, et al: DC-STAMP is essential for cell-cell fusion in osteoclasts and foreign body giant cells. J Exp Med 202: 345-351, 2005.

33. Vignery A: Macrophage fusion: the making of osteoclasts and giant cells. J Exp Med 202: 337-340, 2005.

34. Donn RP, Shelley E, Ollier WE and Thomson W: A novel 5 '-flanking region polymorphism of macrophage migration inhibitory factor is associated with systemic-onset juvenile idiopathic arthritis. Arthritis Rheum 44: 1782-1785, 2001.

35. De Benedetti F, Meazza C, Vivarelli M, et al: Functional and prognostic relevance of the -173 polymorphism of the macrophage migration inhibitory factor gene in systemic-onset juvenile idiopathic arthritis. Arthritis Rheum 48: 1398-1407, 2003.

36. Lehtinen A, Oksa T, Helenius $\mathrm{H}$ and Rönning O: Advanced dental maturity in children with juvenile rheumatoid arthritis. Eur J Oral Sci 108: 184-188, 2000. 